\title{
Signaling Pathway for Endothelin-1- and Phenylephrine-Induced cAMP Response Element Binding Protein Activation in Rat Ventricular Myocytes: Role of Inositol 1,4,5-Trisphosphate Receptors and CaMKII
}

\author{
Krishna P. Subedia,b Min-Jeong Son ${ }^{a}$ Bojjibabu Chidipi ${ }^{a}$ Seong-Woo Kim ${ }^{a}$ \\ Jun Wang ${ }^{\mathrm{a}}$ Kyeong-Hee Kim ${ }^{\mathrm{a}}$ Joon-Chul Kim ${ }^{\mathrm{a}}$ Sun-Hee Woo \\ ${ }^{a}$ College of Pharmacy, Chungnam National University, Yuseong-gu, Daejeon, South Korea; ${ }^{b}$ current \\ address: Secretory Physiology Section, Molecular Physiology and Therapeutics Branch, National \\ Institute of Dental and Craniofacial Research, NIH, Bethesda, MD, USA
}

\section{Key Words}

CAMP response element binding protein - Inositol 1,4,5-trisphosphate receptor - Protein kinase $\mathrm{C} \cdot \mathrm{Ca}^{2+}$-calmodulin-dependent protein kinase II $\bullet$ Ventricular myocytes

\begin{abstract}
Background/Aims: Endothelin-1 (ET-1) and the $\alpha_{1}$-adrenoceptor agonist phenylephrine (PE) activate CAMP response element binding protein (CREB), a transcription factor implicated in cardiac hypertrophy. The signaling pathway involved in CREB activation by these hypertrophic stimuli is poorly understood. We examined signaling pathways for ET-1- or PE-induced cardiac CREB activation. Methods: Western blotting was performed with pharmacological and genetic interventions in rat ventricular myocytes. Results: ET-1 and PE increased CREB phosphorylation, which was inhibited by blockade of phospholipase $C$, the extracellular-signal-regulated kinase 1/2 (ERK1/2) pathway, protein kinase C (PKC) or $\mathrm{Ca}^{2+}$-calmodulin-dependent protein kinase II (CaMKII). Intracellular $\mathrm{Ca}^{2+}$ buffering decreased ET-1- and PE-induced CREB phosphorylation by $\geq 80 \%$. Sarcoplasmic reticulum $\mathrm{Ca}^{2+}$ pump inhibitor, inositol 1,4,5-trisphosphate receptor $\left(\mathrm{IP}_{3} \mathrm{R}\right)$ blockers, or type $2 \mathrm{IP}_{3} \mathrm{R}\left(\mathrm{IP}_{3} \mathrm{R} 2\right)$ knock-out abolished ET-1- or PE-induced CREB phosphorylation. ET-1 and PE increased phosphorylation of CaMKII and ERK1/2, which was eliminated by IP ${ }_{3} R$ blockade/knock-out or PKC inhibition. Activation of CaMKII, but not ERK1/2, by these agonists was sensitive to $\mathrm{Ca}^{2+}$ buffering or to Gö6976, the inhibitor of $\mathrm{Ca}^{2+}$-dependent PKC and protein kinase D (PKD). Conclusion: CREB phosphorylation by ET-1 and PE may be mainly mediated by $\mathrm{IP}_{3} \mathrm{R} 2 / \mathrm{Ca}^{2+}-\mathrm{PKC}-\mathrm{PKD}-\mathrm{CaMKII}$ signaling with a minor contribution by ERK1/2, linked to $\mathrm{IP}_{3} \mathrm{R} 2$ and $\mathrm{Ca}^{2+}$-independent PKC, in ventricular myocytes.
\end{abstract}




\section{Cellular Physiology Cell Physiol Biochem 2017;41:399-412

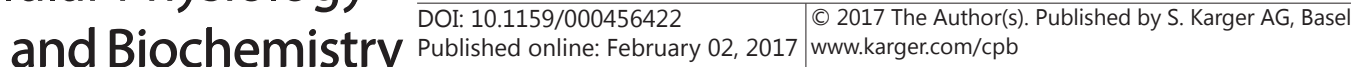

Subedi et al.: Mechanisms for ET-1/PE-Mediated CREB Activation in Ventricle

\section{Introduction}

Neurohumoral hormones such as endothelin-1 (ET-1) or the $\alpha_{1}$-adrenoceptor (AR) agonist phenylephrine (PE) stimulate hypertrophic growth of cardiac myocytes [1]. PE and ET-1 commonly activate phospholipase C (PLC) via $\mathrm{G}_{\mathrm{q}}$-coupled receptors to produce inositol 1,4,5-trisphosphate $\left(\mathrm{IP}_{3}\right)$ and diacylglycerol from phosphatidylinositol 4,5-bisphosphates, thereby inducing $\mathrm{IP}_{3}$ receptor $\left(\mathrm{IP}_{3} \mathrm{R}\right)$-mediated $\mathrm{Ca}^{2+}$ release and protein kinase $\mathrm{C}$ (PKC) activation $[2,3]$. It has been shown in ventricular myocytes that type $2 \mathrm{IP}_{3} \mathrm{Rs}\left(\mathrm{IP}_{3} \mathrm{R} 2\right)$, the major $\mathrm{IP}_{3} \mathrm{R}$ subtype, are localized in the nuclear envelope [4, 5], intercalated discs [6], and in the dyadic junctional sarcoplasmic reticulum [7]. Nuclear $\mathrm{IP}_{3} \mathrm{Rs}$-mediated $\mathrm{Ca}^{2+}$ signal has been proposed to modulate $\mathrm{Ca}^{2+}$-calmodulin-dependent protein kinase (CaMK) II (CaMKII), histone deacetylases (HDAC), and calcineurin-NFATc signaling in ventricular myocytes $[1,5$, 8]. These mechanisms are implicated in transcriptional regulation of hypertrophy-specific genes [5, 9-12]. IP ${ }_{3} \mathrm{R} 2$ proteins are up-regulated in cardiac hypertrophy and failure [13] via positive feedbak regulation of the calcineurin-NFATc signaling pathway [14].

The adenosine 3',5'-monophosphate (cAMP) response element-binding protein (CREB) functions as a $\mathrm{Ca}^{2+}$ - and cAMP-regulated transcription factor for certain genes $[15,16]$. Phosphorylation of $\mathrm{Ser}^{133}$ in CREB by different kinases, including protein kinase A, CaMKs, p90 ribosomal S6 kinases and mitogen- and stress-activated protein kinases (MSKs), results in recruitment of the co-activator CREB-binding protein, thus augmenting CREB-induced gene transcription [15-20]. It has been shown that PE and ET-1 promote CREB phosphorylation in rat cardiac myocytes [21, 22], but not in mouse perfused heart preparations [23]. CREB phosphorylation is implicated in the regulation of expression of genes involved in cardiac hypertrophic changes [21, 22]. ET-1- or PE-induced CREB phosphorylation was shown to be mediated by either extracellular signal-regulated kinase1/2 (ERK1/2) or p38 mitogen activated protein kinase (MAPK) signaling in rat ventricular myocytes [21, 22, 24]. Because the ERK1/2 cascade involved in the ET-1- or PE-induced cardiac CREB phosphorylation was suppressed by a PKC inhibitor [24], it was postulated that CREB activation by ET-1 or PE is mediated by PKC-ERK1/2 signaling. However, the role of PKC in regulating CREB phosphorylation, as well as its interacting partner molecules in such hormonal signaling, has been unknown. Although IP ${ }_{3}$ R or CaMKII has been known to modulate CREB phosphorylation in other tissues, such as skeletal muscle [25], neurons [26], and cholangiocytes [27], whether $\mathrm{IP}_{3} \mathrm{Rs}$ and CaMKII regulate cardiac CREB phosphorylation has been unclear.

Therefore, in this study, we explored signal transduction pathways responsible for CREB phosphorylation in rat ventricular myocytes under the exposure to ET-1 or PE. We examined the potential roles of intracellular $\mathrm{Ca}^{2+}, \mathrm{IP}_{3} \mathrm{Rs}, \mathrm{PKC}$, CaMKII, and ERK1/2 using western blotting combined with pharmacological and genetic interventions. We found that CREB phosphorylations stimulated by either ET- 1 or PE was mainly mediated by CaMKII, that, in turn, was activated by $\mathrm{IP}_{3} \mathrm{R} 2$-mediated $\mathrm{Ca}^{2+}$ increase and $\mathrm{Ca}^{2+}$-dependent $\mathrm{PKC} /$ protein kinase $\mathrm{D}$ (PKD) signaling in these myocytes. Unlike this signaling pathway, the ERK1/2 activation by ET- 1 and PE was mediated by $\mathrm{IP}_{3} \mathrm{R} 2$ and $\mathrm{Ca}^{2+}$-independent $\mathrm{PKC}$, in a manner resistant to $\mathrm{Ca}^{2+}$ buffering.

\section{Materials and Methods}

\section{Single cell isolation and treatment}

Ventricular myocytes were enzymatically isolated [28] from male Sprague Dawley rats (200-300 g) and from wild-type (WT) and IP ${ }_{3}$ R2 knock-out (KO) mice [29] (C57/B6 background, 3-4 months of age, 24-26 g). This study conforms with the Guiding Principles for the Care and Use of Experimental Animals published by the Korean Food and Drug Administration and Animal and Plant Quarantine Agency in South Korea. The experiments were carried out according to the guidelines laid down by the Chungnam National University Animal Care and Use Committee (Approval No. CNU-00368). Rats or mice were deeply anesthetized with sodium pentobarbital (150 mg/kg, i.p.), the chest cavity was opened, and the hearts were excised. This 


\section{Cellular Physiology Cell Physiol Biochem 2017;41:399-412

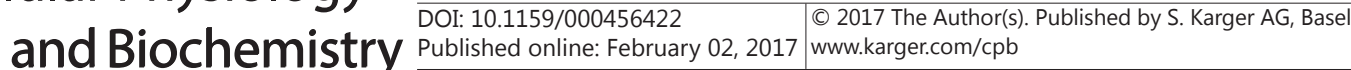

Subedi et al.: Mechanisms for ET-1/PE-Mediated CREB Activation in Ventricle

surgical procedure was carried out in accordance with the university's ethical guidelines. The excised hearts were retrogradely perfused at $7 \mathrm{ml} / \mathrm{min}$ through the aorta, first for $3 \mathrm{~min}$ with a $\mathrm{Ca}^{2+}$-free Tyrode solution composed of (in mM): $137 \mathrm{NaCl}, 5.4 \mathrm{KCl}, 10 \mathrm{HEPES}, 1 \mathrm{MgCl}_{2}, 10$ glucose, and $\mathrm{pH} \mathrm{7.3,} \mathrm{at} 36.5^{\circ} \mathrm{C}$; and then with a $\mathrm{Ca}^{2+}$-free Tyrode solution containing collagenase $(1.4 \mathrm{mg} / \mathrm{ml}$, Type 1 , Roche) and protease $(0.14 \mathrm{mg} /$ $\mathrm{ml}$, Type XIV, sigma) for $12 \mathrm{~min}$; and finally with Tyrode solution containing $0.2 \mathrm{mM} \mathrm{CaCl}$ for $8 \mathrm{~min}$. The ventricles of the digested heart were then cut into several sections and subjected to gentle agitation to dissociate the cells. The $\mathrm{Ca}^{2+}$ concentration of Tyrode solution was gradually increased to $2 \mathrm{mM}$. The cells were then gently resuspended in the Tyrode solution containing ET-1 (100 nM) or PE $(100 \mu \mathrm{M})$ or other inhibitors and incubated at $37^{\circ} \mathrm{C}$ for indicated durations.

\section{Western blotting}

After stimulation for the desired time periods, cells were solubilized in SDS lysis buffer containing 10 $\mathrm{mM}$ Tris-HCl, pH 7.4, 1\% (w/v) SDS, $1 \mathrm{mM}$ phenylmethanesulfonyl fluoride, $1 \mathrm{mM} \mathrm{Na}_{3} \mathrm{VO}_{4}$ and complete protease inhibitor mixture (Roche Molecular Biochemicals) for $10 \mathrm{~min}$ at $70^{\circ} \mathrm{C}$, and then triturated several times by passing through a 1-ml syringe and centrifuged at 12,000 g for $10 \mathrm{~min}$. The supernatant was combined with $2 \times$ Laemmli sample buffer (Bio-Rad, Hercules, CA, USA) and heated for $10 \mathrm{~min}$ at $70^{\circ} \mathrm{C}$. Protein samples were separated by $10 \%$ SDS-PAGE and electroblotted on to nitrocellulose membranes. Total CREB, phospho-CREB, CaMKII, phospho-CaMKII, ERK1/2 and phospho-ERK1/2 were detected with antibodies that specifically recognize the proteins (CREB: Cell signaling technology, \#9197S, rabbit monoclonal Ab; Ser ${ }^{133}$-phosphorylated CREB: Cell signaling technology, \#9198S, rabbit monoclonal Ab; p44/42 MAPK (ERK1/2): Cell signaling technology, \#9102, rabbit polyclonal Ab; $\mathrm{Thr}^{202} / \mathrm{Tyr}^{204}$-phosphorylated p44/42 MAPK (ERK1/2): Cell signaling technology, \#9101S, rabbit polyclonal Ab; CaMKII: Abcam, \#ab52476, rabbit monoclonal Ab; Thr ${ }^{286}$-phosphorylated CaMKII: Cell signaling technology, \#3361S, rabbit polyclonal $\mathrm{Ab}$ ) using a standard Western blot protocol. All blots were imaged and quantified using a ChemiDoc XRS densitometer (Bio-Rad).

\section{Statistics}

Results are mean \pm SEM with significance $(P<0.05)$ determined using unpaired 2-tailed Student's $t$ test. $n$ indicates the number of Western blotting experiments.

\section{Results}

ET-1 and PE stimulate CREB phosphorylation through ET ${ }_{A}$ receptor and $\alpha_{1}$-adrenoceptor, respectively

Enhancement of CREB phosphorylation at $\operatorname{Ser}^{133}$ by ET-1 and PE was demonstrated, respectively, in primary cultures of neonatal rat cardiac myocytes [21] and in adult rat ventricular myocytes, respectively [22]. We first confirmed, by western blotting, whether CREB phosphorylation is increased in isolated adult rat ventricular myocytes treated with these agonists, and further investigated hormonal receptors that mediate these responses. Myocytes were incubated with ET-1 $(100 \mathrm{nM})$ or PE $(100 \mu \mathrm{M})$ for $15 \mathrm{~min}$, because these agonists maximally affected $\mathrm{Ca}^{2+}$ transients and CREB phosphorylation under these conditions [21, 22]. CREB phosphorylation was significantly enhanced by ET-1 and PE (Fig. 1A). To estimate the effects of the agonists on phosphorylating potency, the level of the phosphorylated CREB was normalized to the signal for total CREB and then the ratios for agonist-treated samples were normalized again to the ratio for the control (upper graphs in the figures). CREB activation by ET-1 was almost completely suppressed by pre-treating cells with the ET receptor blocker BQ123 (1 $\mu \mathrm{M}, 30 \mathrm{~min})$ (Fig. 1A). The $\mathrm{ET}_{\mathrm{B}}$ receptor blocker BQ788 did not affect the ET-1-induced CREB activation (Data not shown). Similarly, CREB phosphorylation by PE was suppressed by $\sim 80 \%$ by the $\alpha_{1}$-adrenoceptor antagonist prazosin ( $5 \mu \mathrm{M}, 10 \mathrm{~min}$ ) (Fig. 1A). The residual small increase in CREB phosphorylation after PE stimulation, in the presence of prazosin, may have been mediated by the $\beta$-adrenergic receptor [22]. This result indicates that both ET-1 and PE can stimulate CREB phosphorylation in ventricular myocytes, primarily through $\mathrm{ET}_{\mathrm{A}}$ receptors and $\alpha_{1}$-adrenoceptors, respectively. 


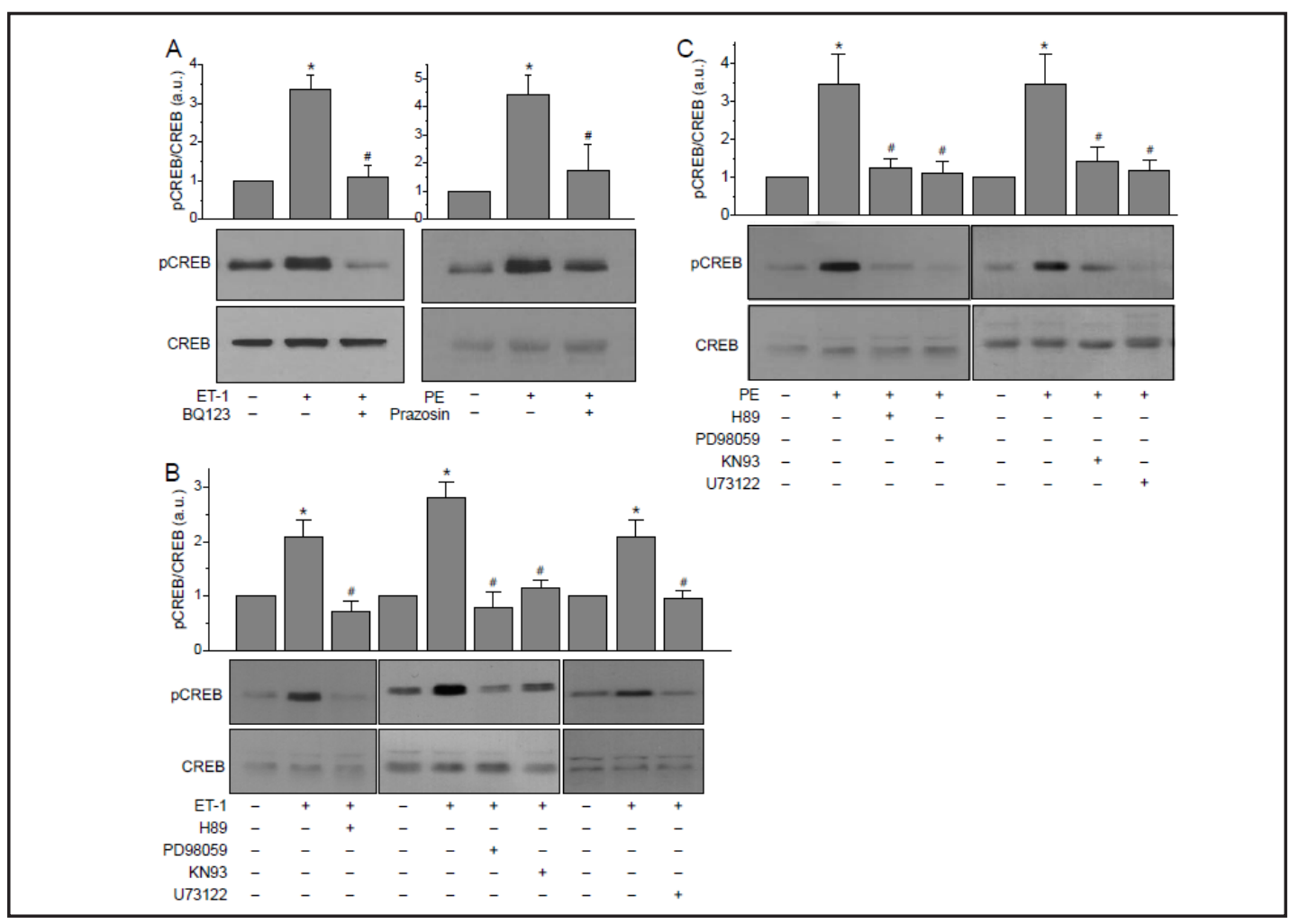

Fig. 1. Enhancement of CREB phosphorylation by ERK1/2 signaling, CaMKII and PLC under the stimulation of $\mathrm{ET}_{\mathrm{A}}$ receptors and $\alpha_{1}$-adernoceptors in rat ventricular myocytes. Upper panels show comparison of quantitative levels of phosphorylated CREB relative to the total CREB (normalized to control) shown in the Western blot analysis below. Fifty- $\mu$ g cell extracts were subjected to SDS/PAGE and immunoblotted for phosphorylated CREB (middle panels) and total CREB (lower panels). (A) Ventricular myocytes were unstimulated or exposed to endothelin-1 (ET-1) (100 nM, $15 \mathrm{~min}$ ) or phenylephrine (PE) (100 $\mu \mathrm{M}, 15 \mathrm{~min})$ without and with $\mathrm{ET}_{\mathrm{A}}$ receptor antagonist BQ123 (1 $\mu \mathrm{M}, 30 \mathrm{~min}$; left) or $\alpha_{1}$-adrenoceptor inhibitor prazosin ( $5 \mu \mathrm{M}, 10 \mathrm{~min}$; right). Four series of experimental results were quantified. ${ }^{*} P<0.05$ vs. each control (untreated). ${ }^{\#} P<0.05$ vs. ET-1 (left) or PE (right). (B and C) Ventricular myocytes were either not exposed to inhibitors (control) or pretreated for 15 min with H89 (25 $\mu \mathrm{M})$, PD98059 (10 $\mu \mathrm{M})$, or 20 min with KN93 (1 $\mu \mathrm{M})$, U73122 (5 $\mu \mathrm{M})$. Then the pretreated cells were exposed to $100 \mathrm{nM}$ ET-1 (B) or $100 \mu \mathrm{M}$ PE (C) for 15 min. Four series of experimental results were quantified. ${ }^{*} P<0.05 v s$. control (untreated). ${ }^{\#} P<0.05 v s$. ET-1 (B) or PE (C).

Role of ERK1/2-MSK1 signaling, PLC and CaMKII in ET-1- and PE-induced CREB phosphorylation

It has been previously demonstrated that PE and ET-1 cause MSK1 phosphorylation via PKC-ERK1/2 signaling and p38 MAPKs in adult rat ventricular myocytes [24]. In addition, the ERK1/2-MSK1 signaling cascade mediates the CREB phosphorylation induced by ET-1 in neonatal rat cardiac myocytes [18] and by PE in adult rat ventricular myocytes [22]. We first confirmed in rat ventricular myocytes whether ERK1/2-MSK1 signaling mediates both ET-1- and PE-induced CREB phosphorylation in rat ventricular myocytes. We used PD98059, a drug inhibiting activation of MAPK kinase-1 (also called MEK1 or ERK kinase) and, hence, the activation of MAPKs/ERKs. We also used H89, a drug suppressing several kinases and a potent MSK1 inhibitor [30]. In cells exposed to $100 \mathrm{nM}$ ET-1 or $100 \mu \mathrm{M}$ PE for $15 \mathrm{~min}$, CREB phosphorylation was increased, and in both cases this was completely inhibited by pre-treatment with H89 (25 $\mu \mathrm{M}, 15 \mathrm{~min}$ ) or PD98059 (10 $\mu \mathrm{M}, 10 \mathrm{~min}$ ) (Fig. 1B and C). These results suggest that both ET-1 and PE activate CREB via MEK1-ERK1/2-MSK1 signaling, consistent with the previous reports in neonatal and adult rat ventricular myocytes [21, 22]. 


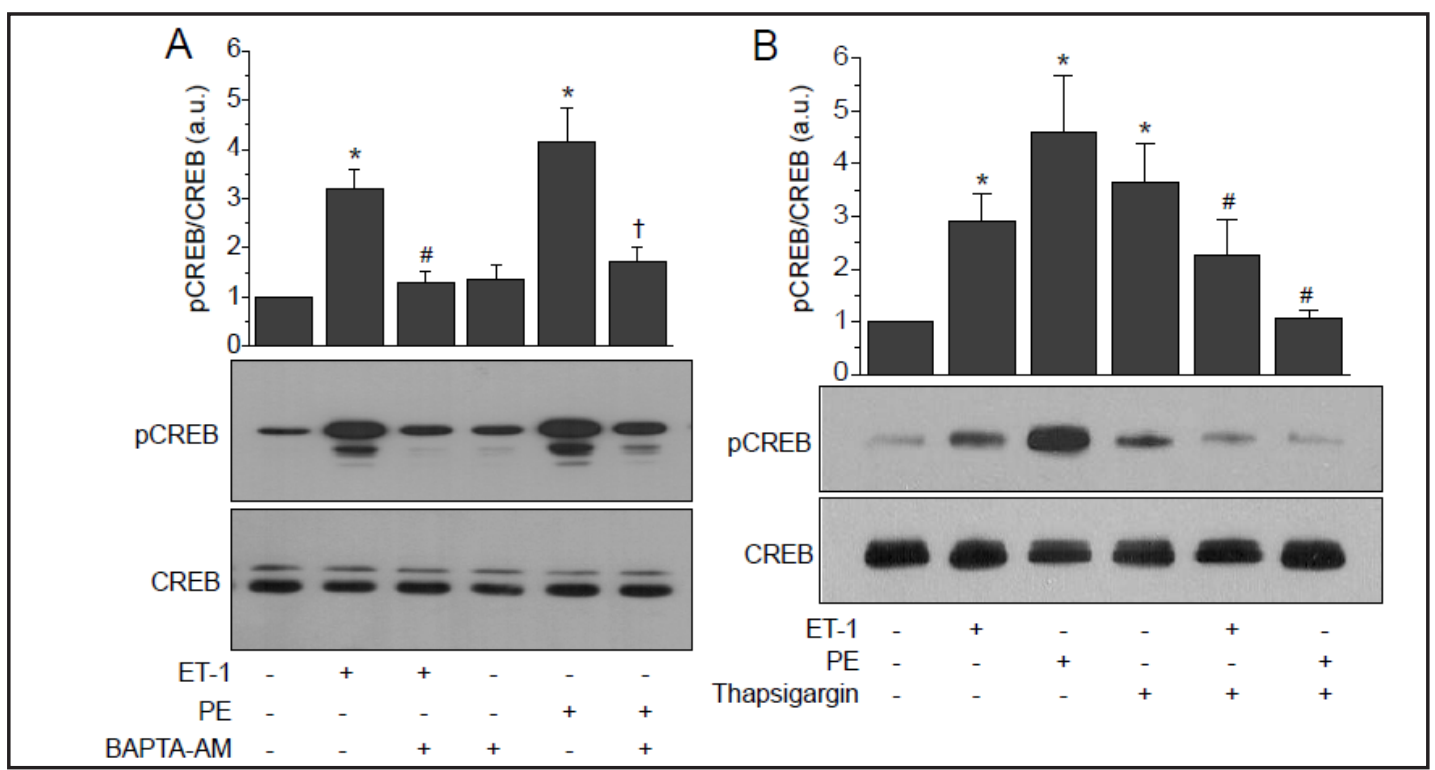

Fig. 2. Roles of global $\mathrm{Ca}^{2+}$ increase and $\mathrm{SR} \mathrm{Ca}^{2+}$ release in the enhancement of CREB phosphorylation by ET-1 and PE. Ventricular myocytes were either not exposed to interventions (control) or pretreated for 30 min with BAPTA-AM (10 $\mu \mathrm{M}$; A) or for 10 min with thapsigargin $(1 \mu \mathrm{M}$ : B), and then treated with ET-1 or PE for 15 min. Upper panels show comparison of quantitative levels of phosphorylated CREB relative to the total CREB (normalized to control) shown in the Western blot analysis below. Fifty- $\mu$ g cell extracts were subjected to SDS/PAGE and immunoblotted for phosphorylated CREB (middle panels) and total CREB (lower panels). Four and five series of experiments were quantified in BAPTA and thapsigargin, respectively. ${ }^{*} P$ $<0.05$ vs. control (untreated). ${ }^{\#} P<0.05$ vs. ET-1 (A) or thapsigargin (B). ${ }^{\dagger} P<0.05$ vs. PE.

Receptors for ET-1 and PE are G-protein coupled and commonly activate PLC signaling, thereby activating $\mathrm{IP}_{3} \mathrm{Rs}$ and $\mathrm{PKC}$ and mobilizing intracellular $\mathrm{Ca}^{2+}$ in cardiac myocytes $[2$, 3, 31-33]. Both ET-1 and PE were reported to activate CaMKII in cardiac myocytes, thereby regulating excitation-contraction coupling and gene transcription [5, 34, 35]. However, the role of CaMKII in the enhancement of CREB phosphorylation by ET- 1 and PE is not known. We tested its involvement using the CaMKII inhibitor KN93 (1 $\mu \mathrm{M}, 20 \mathrm{~min})$. Stimulation of CREB phosphorylation by ET- 1 was suppressed to $10 \%-15 \%$ in cells pretreated with KN93 (Fig. 1B), while the response to PE was inhibited by KN93 to approximately 30\% (Fig. 1C). Stimulation of CREB phosphorylation by ET-1 or PE was eliminated by the PLC inhibition (U73122, $5 \mu \mathrm{M}, 20$ min; Fig. 1B and C). These results suggest that CaMKII and PLC, in addition to the ERK1/2 signaling, may mediate ET-1- and PE-stimulated CREB phosphorylation.

Role of SR $\mathrm{Ca}^{2+}$ release and $I P_{3} R 2$ in the enhancement of CREB phosphorylation by ET-1 and $P E$

We next examined whether cytosolic $\mathrm{Ca}^{2+}$ increase plays a role in the enhancement of CREB phosphorylation by $\alpha_{1}$-adrenoceptor and $\mathrm{ET}_{\mathrm{A}}$ receptor stimulation. When cytosolic $\mathrm{Ca}^{2+}$ was buffered by loading the cells with BAPTA-AM $(10 \mu \mathrm{M})$ for $30 \mathrm{~min}$, CREB phosphorylation was only slightly increased, by about $10 \%$, by subsequent stimulation with ET-1. Under this condition, PE-induced CREB phosphorylation was suppressed by about $70 \%-80 \%$ with cytosolic $\mathrm{Ca}^{2+}$ buffering (Fig. 2A). To further examine whether $\mathrm{Ca}^{2+}$ release from the sarcoplasmic reticulum (SR) plays a role in ET-1- and PE-induced CREB phosphorylation, $\mathrm{Ca}^{2+}$ in the SR lumen was depleted using the $\mathrm{SR} \mathrm{Ca}^{2+}$ pump inhibitor, thapsigargin (1 $\mathrm{M}, 10 \mathrm{~min}$ ). Exposure to thapsigargin alone increased CREB phosphorylation (Fig. 2B). This effect was similar to that of ET-1 or PE on CREB phosphorylation and might be stimulated by increased $\mathrm{Ca}^{2+}$ levels caused by decreased cytosolic $\mathrm{Ca}^{2+}$ uptake into the SR. This result was consistent with previous reports of the $\mathrm{Ca}^{2+}$-dependence of CREB phosphorylation 


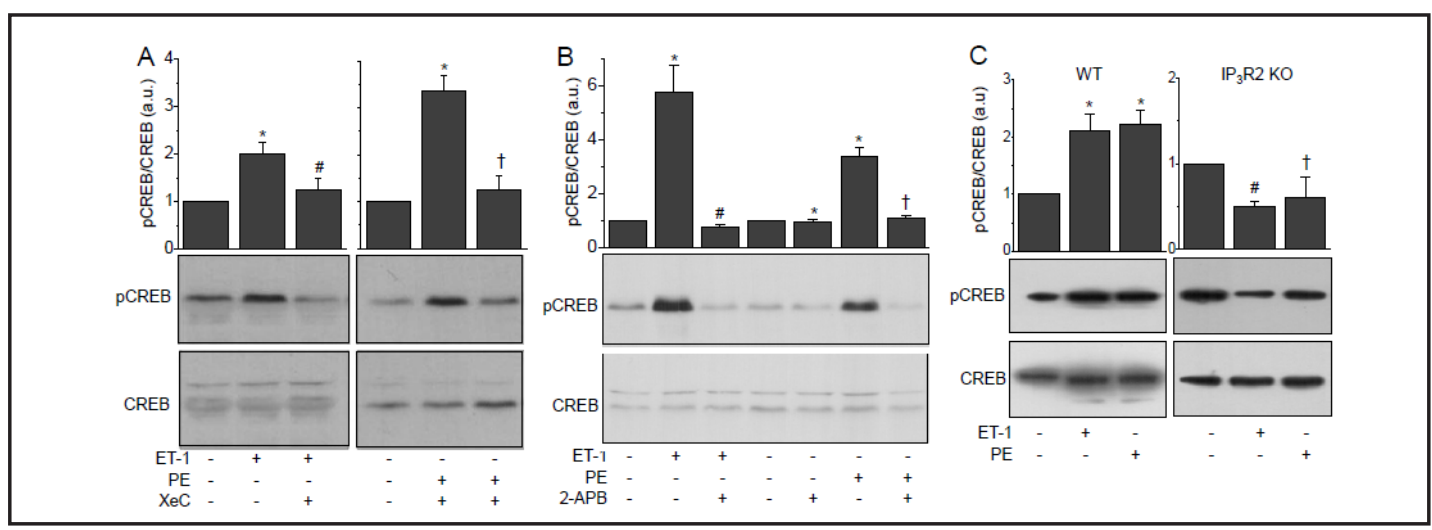

Fig. 3. Role of IP ${ }_{3}$ R2 in ET-1- and PE-induced CREB phosphorylation. Ventricular myocytes were either not exposed to interventions (control) or pretreated for $45 \mathrm{~min}$ with $10 \mu \mathrm{M}$ xestospongin $\mathrm{C}(\mathrm{XeC} ; \mathrm{A} ; n=4)$ or for 30 min with $3 \mu \mathrm{M}$ 2-APB (B; $n=4$ ), and then treated with ET- 1 or PE for 15 min. ${ }^{*} P<0.05$ vs. control (untreated). ${ }^{\#} P<0.05$ vs. ET- $1 .{ }^{\dagger} P<0.05$ vs. PE. Upper panels show comparison of quantitative levels of phosphorylated CREB relative to the total CREB (normalized to control) shown in the Western blot analysis below. Fifty- $\mu$ g cell extracts were subjected to SDS/PAGE and immunoblotted for phosphorylated CREB (middle panels) and total CREB (lower panels). (C) Western blotting analysis for phosphorylated CREB and CREB in wild-type (WT; $n=3$ ) and IP ${ }_{3}$ R2 knock-out (KO; $n=3$ ) mouse ventricular myocytes without and with ET-1 or PE. ${ }^{*} P<0.05 v s$. control (untreated). ${ }^{\#} P<0.05 v s$. WT ET- $1 .{ }^{\dagger} P<0.05$ vs. WT PE.
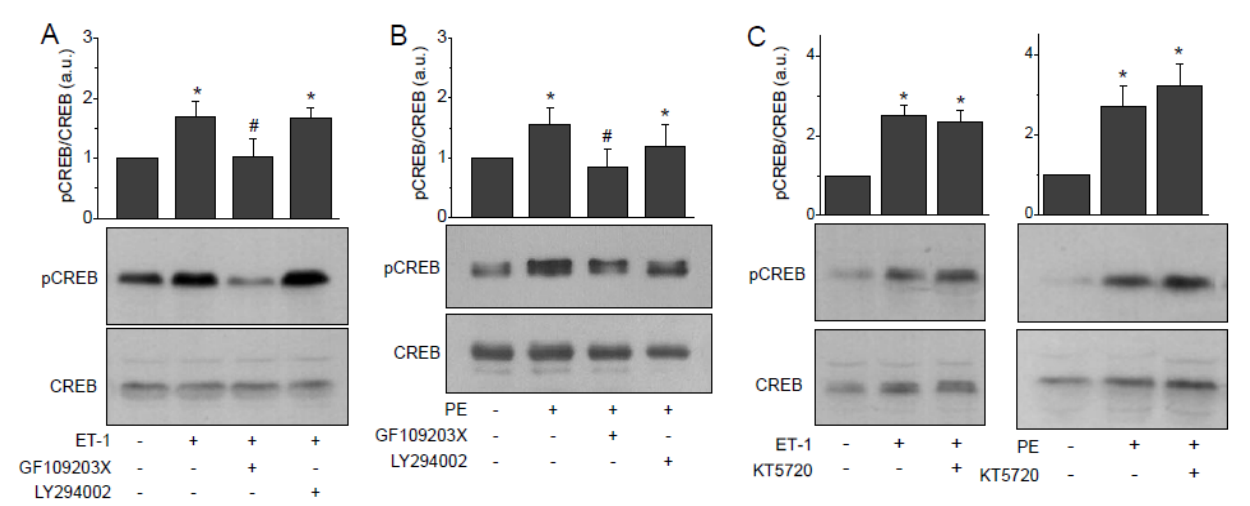

Fig. 4. Role of PKC in ET-1 and PE-induced CREB phosphorylation. Ventricular myocytes were either not exposed to interventions (control) or pretreated for 10 min with PKC inhibitor GF109203X (5 $\mu$ M, $n=4$; A and B), for 45 min with PI3K inhibitor LY294002 ( $50 \mu \mathrm{M} ; n=4$; A and B), or for 30 min with PKA blocker KT5720 ( $5 \mu \mathrm{M} ; n=3$; C). Then the cells were treated with ET-1 or PE for $15 \mathrm{~min}$. Upper panels show comparison of quantitative levels of phosphorylated CREB relative to the total CREB (normalized to control) shown in the Western blot analysis below. Fifty- $\mu$ g cell extracts were subjected to SDS/PAGE and immunoblotted for phosphorylated CREB (middle panels) and total CREB (lower panels). ${ }^{*} P<0.05$ vs. control (untreated). ${ }^{\#} P<$ 0.05 vs. ET-1 (A) or PE (B).

[16]. Application of ET-1 to the cells pre-exposed to thapsigargin did not further increase CREB phosphorylation. PE treatment decreased the CREB phosphorylation levels that had already been increased by thapsigargin (Fig. 2B). These data indicate that increase in CREB phosphorylation by ET-1 and PE may be mainly caused by intracellular $\mathrm{Ca}^{2+}$ increase due to $\mathrm{SR} \mathrm{Ca}^{2+}$ release.

To identify the $\mathrm{Ca}^{2+}$ release pathway responsible for ET-1- or PE-stimulated CREB phosphorylation, we investigated the role of $\mathrm{IP}_{3} \mathrm{Rs}$, activated by $\mathrm{ET}_{\mathrm{A}} / \alpha_{1}$-adrenergic receptor signaling. Both ET-1- and PE-induced increases in the CREB phosphorylation were inhibited by treatment of either xestospongin $\mathrm{C}(10 \mu \mathrm{M})$ or 2 -APB $(3 \mu \mathrm{M})$, the $\mathrm{IP}_{3} \mathrm{R}$ blockers (Fig. 3A and $B)$. Because these inhibitors are not specific for $\operatorname{IP}_{3} \mathrm{Rs}[36,37]$, we confirmed the role 
Fig. 5. Activation of CaMKII by ET-1 and PE via $\mathrm{IP}_{3} \mathrm{R}$, intracellular $\mathrm{Ca}^{2+}$ increase, and $\mathrm{Ca}^{2+}$-dependent $\mathrm{PKC} / \mathrm{PKD}$. Ventricular myocytes were either not exposed to interventions (control) or pretreated for 30 min with $3 \mu \mathrm{M}$ 2-APB (A; $n=$ 4 ) or $10 \mu \mathrm{M}$ BAPTA (B; $n=4)$. Then the cells were additionally treated with ET-1 (100 nM) or PE (100 $\mu \mathrm{M}$ ) for $15 \mathrm{~min}$. Inhibition of IP $_{3}$ Rs or $\mathrm{Ca}^{2+}$ buffering inhibited ET1- and PE-induced CaMKII phosphorylation. Upper panels show comparison of quantitative levels of phosphorylated CaMKII relative to the total CaMKII (normalized to control) shown in the Western blot analysis below. (C) Pretreatment of chelerythrine (5 $\mu \mathrm{M}, 30 \mathrm{~min})$ or Gö6976 (10 $\mu \mathrm{M}, 15 \mathrm{~min})$ significantly suppressed increase in CaMKII phosphorylation by ET-1 or PE $(n=5)$. Fifty- $\mu$ g cell extracts were subjected to SDS/PAGE and immunoblotted for phosphorylated CaMKII (middle panels) and total CaMKII (lower panels). ${ }^{*} P<$ 0.05 vs. control (untreated). ${ }^{\#} P<$ 0.05 vs. ET $-1 .{ }^{\dagger} P<0.05$ vs. PE.

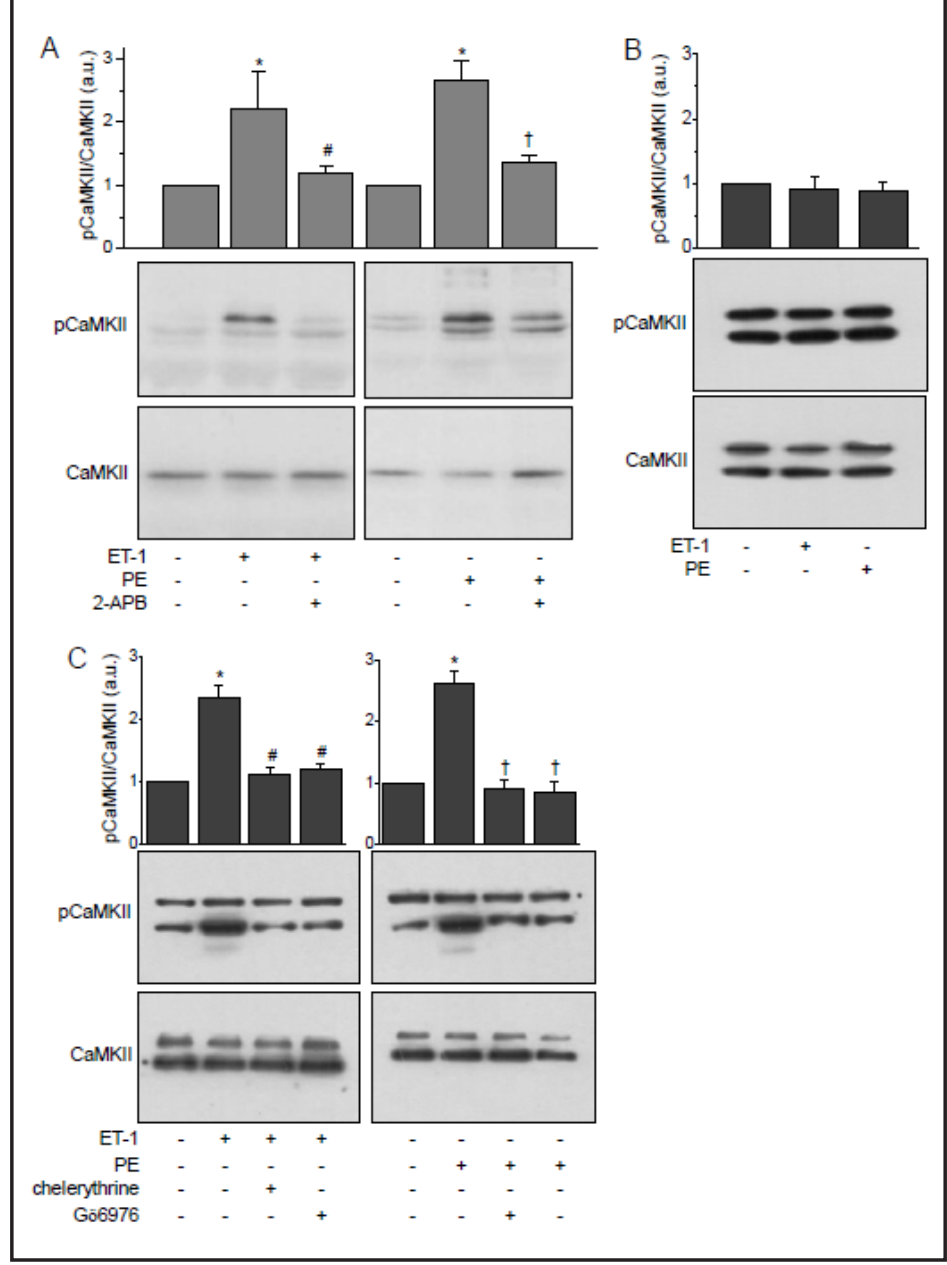

of $\mathrm{IP}_{3} \mathrm{Rs}$ in these hormonal responses by using ventricular myocytes from $\mathrm{IP}_{3} \mathrm{R} 2 \mathrm{KO}$ mice. In WT myocytes, ET-1 or PE treatment consistently increased CREB phosphorylation (Fig. 3C). In sharp contrast, neither ET-1 nor PE increased the CREB phosphorylation in the IP ${ }_{3} \mathrm{R} 2 \mathrm{KO}$ myocytes (Fig. 3C). In the KO cells, CREB phosphorylation was, instead, decreased by ET-1 or PE (Fig. 3C, right). This was consistent with the observation on decrease in the level of phosphorylated CREB in the presence of 2-APB alone (Fig. 3B). These results suggest that $\mathrm{IP}_{3} \mathrm{R} 2$ plays a key role in the increase of CREB phosphorylation under the stimulation of ET $\mathrm{A}$ receptors or $\alpha_{1}$-adrenoceptors in ventricular myocytes.

\section{Role of PKC in ET-1- and PE-induced CREB phosphorylation}

Previous papers have shown that ERK1/2-MSK1 signaling is an important mediator of the CREB phosphorylation in the presence of ET-1 or PE [21, 22]. In addition, MSK1 activation by these agonists was inhibited by a PKC inhibitor [24]. We also found that increase in CREB phosphoryation by ET-1 and PE was eliminated by inhibitors for ERK1/2 and MSK1 (Fig. 1B and C). Activation of PKC during stimulation of $\alpha_{1}$-adrenoceptors and $\mathrm{ET}_{\mathrm{A}}$ receptors could be facilitated by a $\mathrm{Ca}^{2+}$ increase via activation of $\mathrm{IP}_{3} \mathrm{Rs}$. Therefore, we examined the potential roles of PKC and other important kinases in CREB activation during these hormonal stimulations. Inhibition of PKC by GF109203X (5 $\mu \mathrm{M}, 10 \mathrm{~min}$ ) completely suppressed CREB phosphorylation induced by ET-1 or PE (Fig. 4A). However, blockade of protein kinase A (5 $\mu$ M KT5720, 30 min) or phosphoinositide 3-kinase (50 $\mu$ M LY294002, 45 min) did not alter ET-1- or PE-induced CREB phosphorylation (Fig. 4). These results indicate that PKC may be an important mediator for CREB phosphorylation during the stimulation of $\alpha_{1}$-adrenoceptors and $\mathrm{ET}_{\mathrm{A}}$ receptors.

\section{KARGER}


Fig. 6. Enhancement of ERK1/2 phosphorylation through PLC/Ca ${ }^{2+}$-independent PKC, but not CaMKII. (A) Quantitative comparison of the level of phosphorylated ERK1/2 normalized to total ERK1/2 in the absence and presence of ET-1 (100 nM, $n=3$ ) or PE $(100 \mu \mathrm{M}, n=3)$ in untreated myocytes and in the cells pre-exposed to PKC inhibitor (GF109203X, 5 $\mu \mathrm{M}, 15 \mathrm{~min})$. (B) comparison of the level of phosphorylated ERK1/2 normalized to total ERK1/2 in the absence and presence of ET- $1(n=4)$ or PE $(n=$ 3 ) in untreated myocytes and in the cells pre-incubated with CaMKII inhibitor KN93 (1 $\mu \mathrm{M}, 20 \mathrm{~min})$, MEK1 inhibitor PD98059 (10 $\mu \mathrm{M}, 10 \mathrm{~min})$, or PLC

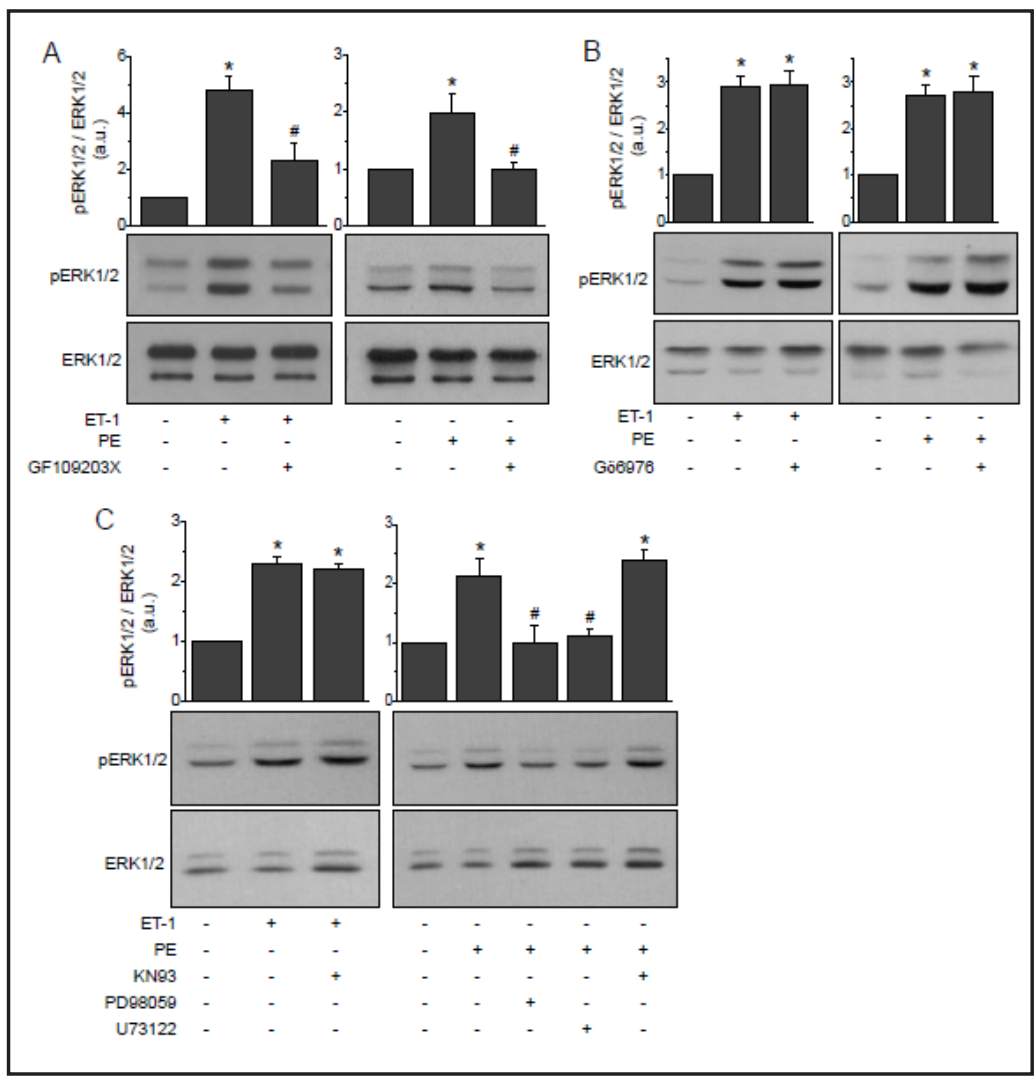
inhibitor U73122 (5 $\mu \mathrm{M}, 20 \mathrm{~min}$ ). (C) Comparison of the level of phosphorylated ERK1/2 normalized to total ERK1/2 showing no change in the level of ERK1/2 phosphorylation by ET-1 or PE in the presence of Gö6976 (10 $\mu \mathrm{M}, 15 \mathrm{~min} ; n=3)$. Fifty- $\mu \mathrm{g}$ cell extracts were subjected to SDS/PAGE and immunoblotted for phosphorylated ERK1/2 (middle panels) and total ERK1/2 (lower panels). ${ }^{*} P<0.05$ vs. control (untreated). ${ }^{\#} P<0.05$ vs. ET- 1 or PE.

\section{Activation of CaMKII by ET-1 and PE via IP ${ }_{3}$ Rs and $\mathrm{Ca}^{2+}$}

After finding evidence for suppression of theET-1-and PE-induced CREB phosphorylation by inhibition of either the CaMKII or the IP ${ }_{3}$ Rs (Figs. 1 and 3), we monitored the phosphorylated form of CaMKII to directly assess its activation in cells treated with these agonists. Both ET-1 and PE significantly increased CaMKII phosphorylation (Fig. 5A). We further tested whether ET-1- or PE-stimulated CaMKII phosphorylation requires activation of the $\mathrm{IP}_{3} \mathrm{Rs}$, using their inhibitor 2-APB. Pre-incubation of the ventricular myocytes with 2-APB (3 $\mu \mathrm{M}$, 30 min) fully suppressed ET-1-induced CaMKII phosphorylation and suppressed PE-induced CaMKII phosphorylation by 70\%-80\% (Fig. 5A). Activation of CaMKII by ET-1 and PE was not observed in the cells pre-loaded with BAPTA ( $10 \mu \mathrm{M}, 30 \mathrm{~min})$ (Fig. 5B), suggesting role of $\mathrm{Ca}^{2+}$ increase in CaMKII activation by these agonists. This result indicates that ET-1 and PE may activate CaMKII mainly via an increase in intracellular $\mathrm{Ca}^{2+}$ through IP ${ }_{3} \mathrm{Rs}$ activation, and that $\mathrm{PE}$ can also cause CaMKII activation, in part, via an $\mathrm{IP}_{3} \mathrm{R}$-independent pathway. This result is also consistent with a previous report that ET-1 induces CaMKII phosphorylation via IP ${ }_{3}$ Rs in rat ventricular myocytes [5]. However, it has also been reported that PE-induced CaMKII phosphorylation is eliminated by PKC blockade in ventricular myocytes [34]. Because our data showed that CREB phosphorylation by ET-1 and PE was sensitive to inhibitors of either PKC or CaMKII (Figs. 1 and 4), we tested whether PKC was involved in CaMKII activation in cells treated with ET-1 or PE. Pre-incubation of cells with the PKC inhibitor chelerythrine (5 $\mu \mathrm{M}, 30 \mathrm{~min}$ ) abolished CaMKII phosphorylation by ET-1 or PE (Fig. 5C). Because inhibition of either $\mathrm{IP}_{3} \mathrm{Rs}$ or PKC suppressed most of the CaMKII activation caused by ET- 1 and PE,

\section{KARGER}


Fig. 7. Enhancement of ERK1/2 phosphorylation by ET-1 and PE via IP ${ }_{3}$ R2, but not global $\mathrm{Ca}^{2+}$ increase. (A) Both ET-1 and PE failed to increase ERK1/2 phosphorylation in the presence of $\mathrm{IP}_{3} \mathrm{R}$ inhibitors 2-APB $(n=3)$ or XeC $(n$ $=3$ ). ${ }^{*} P<0.05$ vs. control (untreated). ${ }^{\#} P<0.05$ vs. ET- $1 .{ }^{\dagger} P<0.05$ vs. PE. (B) ERK1/2 phosphorylation was increased in WT mouse ventricular myocytes by ET-1 $(100 \mathrm{nM})$ or PE $(100 \mu \mathrm{M})(n=$ 3 ), but slightly decreased in $\mathrm{IP}_{3} \mathrm{R} 2 \mathrm{KO}$ myocytes by these agonists $(n=3) .{ }^{*} P$ $<0.05$ vs. control (untreated). ${ }^{*} P<0.05$ vs. WT ET-1 or WT PE. (C) No change in the ERK1/2 phosphorylation by 100 nM ET-1 and $100 \mu \mathrm{M}$ PE in $\mathrm{Ca}^{2+}$-buffered myocytes using BAPTA-AM. Quantitative comparison of the level of phosphorylated ERK1/2 normalized to total ERK1/2 in the absence and presence of ET- 1 or PE in untreated myocytes and in the BAPTA-AM (10 $\mu \mathrm{M}, 30 \mathrm{~min}$ ) pre-incubated myocytes $(n=4)$. Fifty- $\mu$ g cell extracts were subjected to SDS/PAGE and immunoblotted for phosphorylated ERK1/2 (middle panels) and total ERK1/2 (lower panels). ${ }^{*} P<0.05$ vs. control (untreated).

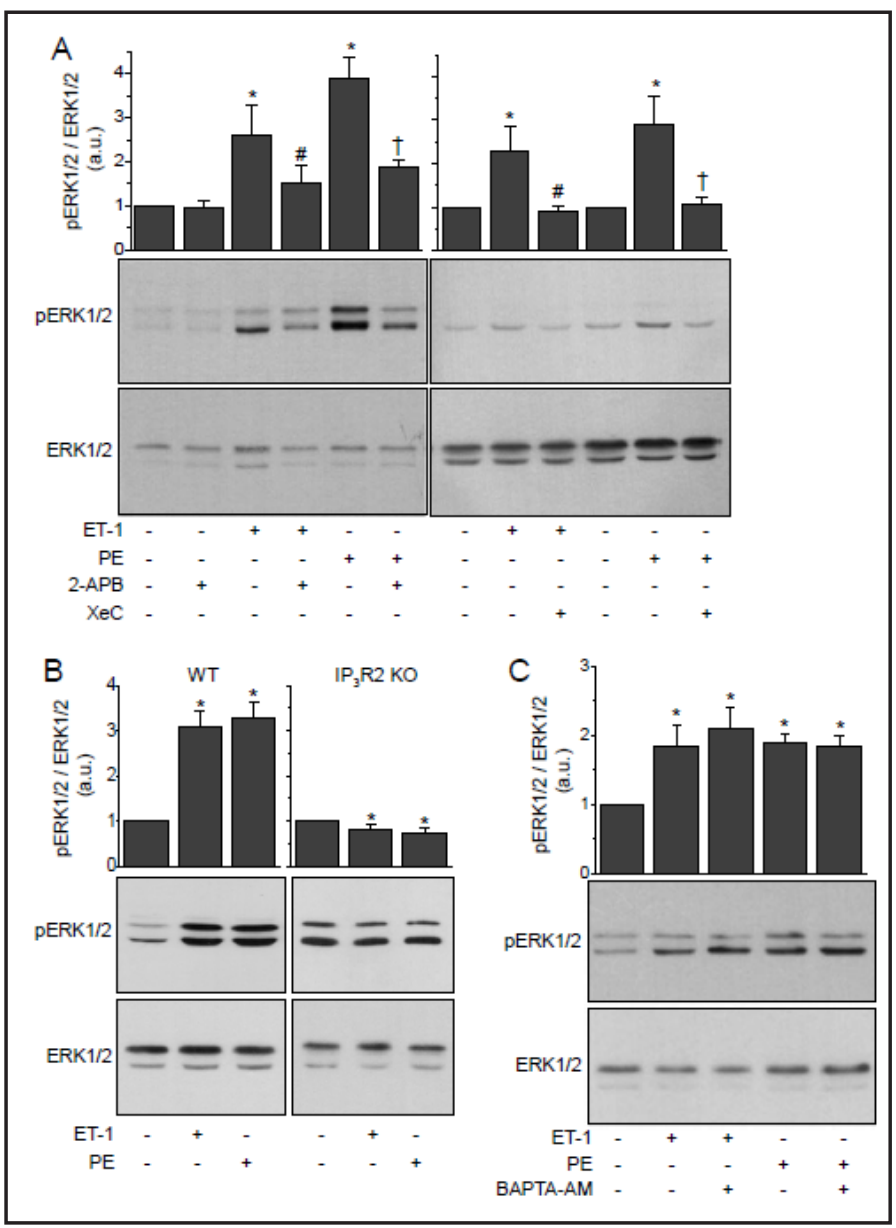

PKC may be the downstream molecule that is activated by $\mathrm{IP}_{3} \mathrm{R}_{-} \mathrm{Ca}^{2+}$ signaling. To test this hypothesis, we repeated our experiments in the presence of the $\mathrm{Ca}^{2+}$-regulated PKC (PKC $\alpha$, $\beta$, and $\mu$ [PKD]) inhibitor Gö6976 (10 $\mu \mathrm{M}, 15 \mathrm{~min})$ [38]. In cells treated with Gö6976, ET-1 or PE did not increase CaMKII phosphorylation (Fig. 5C). These results support the hypothesis that CaMKII is activated by the $\mathrm{Ca}^{2+}$-dependent PKC/PKD via an $\mathrm{IP}_{3} \mathrm{R}$-mediated $\mathrm{Ca}^{2+}$ increase after stimulation of either $\alpha_{1}$-adrenoceptors or $\mathrm{ET}_{\mathrm{A}}$ receptors.

\section{Role of $\mathrm{Ca}^{2+}$-independent $P K C$ and $I P_{3} R 2$ in ERK1/2 activation by ET-1/PE}

Because CREB phosphorylation, stimulated by ET-1 or PE, was prevented either by an ERK inhibitor or by PKC inhibitors (Figs. 1 and 4), we next examined whether ET-1 and PE activate ERK1/2 and the role of PKC in this activation. To estimate ERK1/2 activation, its phosphorylation was measured by western blotting. Application of ET-1 or PE significantly increased levels of phosphorylated ERK1/2 (Fig. 6A). Inhibition of PKC using GF109203X (5 $\mu \mathrm{M}, 10 \mathrm{~min}$ ) suppressed ET-1-induced ERK1/2 phosphorylation by 60\%-70\%, while abolishing the effects of PE (Fig. 6A). Because CaMKII activation by ET- 1 and PE was sensitive to blockade of $\mathrm{Ca}^{2+}$-dependent PKC/PKD (Fig. 5C), we further examined whether ERK1/2 phosphorylation under these hormonal stimulations is also affected by Gö6976. Pre-exposure of cells to Gö6976 (10 $\mu \mathrm{M}, 15 \mathrm{~min})$ did not alter the enhancement of ERK1/2 phosphorylation by ET-1 or PE (Fig. 6B), suggesting no role of $\mathrm{Ca}^{2+}$-dependent PKC/PKD in ERK1/2 activation by ET-1 or PE. Consistently, inhibition of CaMKII using KN93 (1 $\mu \mathrm{M}, 20 \mathrm{~min})$ did not suppress ET-1- or PE-induced ERK1/2 phosphorylation (Fig. 6C). As we hypothesized, ET-1- or PEmediated ERK1/2 phosphorylation was suppressed by PLC inhibition (U73122; Data not shown for ET-1) or by the ERK1/2 pathway inhibitor PD98059 (10 $\mu \mathrm{M}, 15 \mathrm{~min})$ (Fig. 6C). 
Fig. 8. Proposed signal transduction pathway for CREB activation under the stimulation of $\mathrm{ET}_{\mathrm{A}}$ receptor and $\alpha_{1}$-adrenoceptor. Both receptors activate $\mathrm{IP}_{3} \mathrm{R} 2$-mediated $\mathrm{Ca}^{2+}$ releases, which, in turn, activate $\mathrm{Ca}^{2+}$-dependent PKC/PKD-CaMKII signaling, thereby activating CREB. This pathway may be responsible for BAPTA-sensitive $(\geq 80)$ component of CREB phosphorylation. $\mathrm{A} \mathrm{Ca}^{2+}$-independent PKC-ERK1/2 signaling pathway also mediates a smaller portion of CREB phosphorylation under the stimulation of these receptors. $\mathrm{IP}_{3} \mathrm{R} 2$ may play a critical role in the regulation of ERK1/2 activity and the interaction between $\mathrm{IP}_{3} \mathrm{R} 2$ and ERK1/2 appears to occur in a $\mathrm{Ca}^{2+}$-independent manner. CaMKII may, in turn, phosphorylate $\mathrm{IP}_{3} \mathrm{R} 2$, thereby negatively regulating its opening [4].

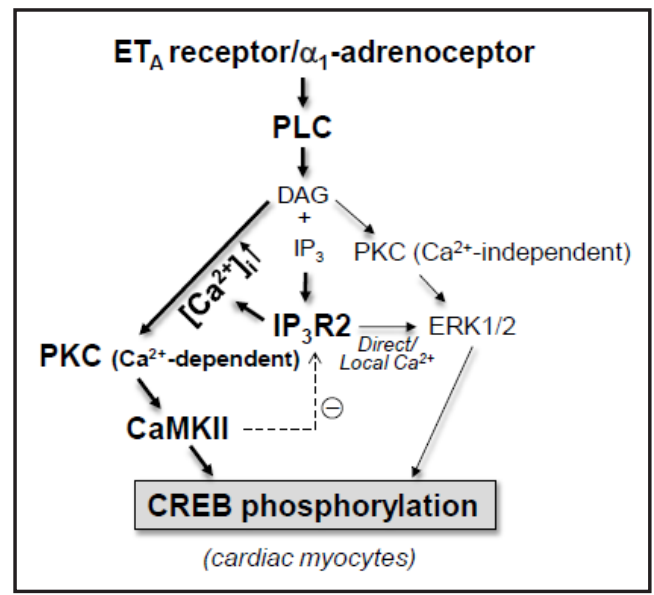

These results suggest that ET- 1 and PE activate ERK1/2 via PLC and $\mathrm{Ca}^{2+}$-independent PKC signaling, but not via CaMKII and PKD.

In the next series of experiments, we examined whether $\mathrm{IP}_{3} \mathrm{Rs}$ and $\mathrm{Ca}^{2+}$ increase regulate ERK1/2 activation under these hormonal stimulations. When $\mathrm{IP}_{3}$ Rs were suppressed using 2-APB or XeC, ET-1- or PE-induced ERK1/2 phosphorylation was significantly decreased (Fig. 7A). To know whether the enhanced ERK1/2 phosphorylation in the presence of ET-1 or PE was caused by $\mathrm{IP}_{3} \mathrm{R} 2$, the level of phosphorylated ERK1/2 was compared in agonist-stimulated ventricular myocytes from WT and $\mathrm{IP}_{3} \mathrm{R} 2 \mathrm{KO}$ mice. In the WT cells, phosphorylated ERK1/2 was higher in the presence of ET-1 or PE (Fig. 7B). In contrast, ET-1 and PE caused a slight decrease in the level of phosphorylated ERK1/2 in the IP ${ }_{3} \mathrm{R} 2 \mathrm{KO}$ cells (Fig. 7B). When the cytosolic $\mathrm{Ca}^{2+}$ increase was suppressed by preincubating cells with the $\mathrm{Ca}^{2+}$ buffer BAPTA-AM $(10 \mu \mathrm{M})$, ET-1 and PE continued to increase ERK1/2 phosphorylation to levels similar to those without BAPTA (Fig. 7C). This result suggests that ERK1/2 signaling may be regulated either directly by $\mathrm{IP}_{3} \mathrm{R} 2$ or through local $\mathrm{Ca}^{2+}$ signaling in a compartment inaccessible to BAPTA.

\section{Discussion}

In this study, we demonstrated that ET-1 and PE stimulate CREB phosphorylation in rat ventricular myocytes by activation of $\mathrm{ET}_{\mathrm{A}}$ receptors and $\alpha_{1}$-adrenoceptors, respectively, through two general effector molecules, CaMKII and ERK1/2, and that CaMKII and ERK1/2 are regulated by $\mathrm{IP}_{3}$ Rs and PKC through PLC (Fig. 8). The CREB activation under these agonists was almost completely eliminated by intracellular $\mathrm{Ca}^{2+}$ buffering using BAPTA or by SR $\mathrm{Ca}^{2+}$ depletion (Fig. 2). Interestingly, of the two major effectors activated by ET-1 and PE, the activity of CaMKII, but not ERK1/2, was sensitive to the $\mathrm{Ca}^{2+}$ buffers (Figs. 5B and 7C), suggesting that $\mathrm{Ca}^{2+}$-dependent activation of CaMKII may play a major role in CREB phosphorylation stimulated by ET-1 or PE. Contrasting effects of Gö6976, the inhibitor of $\mathrm{Ca}^{2+}$-dependent PKC/PKD, on the activation of CaMKII and ERK1/2 by these agonists further indicate that only CaMKII activity is regulated by $\mathrm{Ca}^{2+}$-dependent PKC/PKD (Figs. 5C, 6B and 8). The sensitivity of ERK1/2 phosphorylation to IP $\mathrm{R} 2 \mathrm{KO}$ and its resistance to internal BAPTA suggest that ERK1/2 signaling during the stimulation of $\mathrm{ET}_{\mathrm{A}}$ receptors and $\alpha_{1}$-adrenoceptors may occur in a separate compartment that is more closely localized with IP $\mathrm{R} 2$ and different PKC isozymes. These data also suggest that ERK1/2 signaling is responsible for the portion (10\%-20\%) of CREB phosphorylation resistant to $\mathrm{Ca}^{2+}$ buffering during agonist-induced stimulation (Fig. 8).

Our data provide evidence for the possible role of $\mathrm{IP}_{3}$ Rs and CaMKII in the regulation of gene expression during the stimulation of $\mathrm{ET}_{\mathrm{A}}$ receptor and $\alpha_{1}$-adrenoceptor via activation of CREB. So far, there has been no report showing the role of $\mathrm{IP}_{3} \mathrm{R}$ and CaMKII in CREB 
Fig. 9. Non-specific effects of PD98059 on phosphorylation of CREB and CaMKII. (A) Application of PD98059 (10 $\mu \mathrm{M}, 10 \mathrm{~min}$ ), but not U73122 (5 $\mu \mathrm{M}$, $20 \mathrm{~min}$ ), significantly reduced the level of CREB phosphorylation $(n=4)$. ${ }^{*} P<$ $0.05 v s$. control (untreated). (B) Ventricular myocytes were un-stimulated or exposed to PD98059 (10 $\mu \mathrm{M}, 15 \mathrm{~min})$, or endothelin-1 (ET-1) (100 nM) or PE $(100 \mu \mathrm{M})$ without and with PD98059 $(n=4) .{ }^{*} P<0.05$ vs. control (untreated). ${ }^{\#} P<0.05$ vs. PD98059 alone. Upper panels show comparison of quantitative levels of phosphorylated CREB (A) or CaMKII (B) relative to the total CREB (A) or CaMKII (B) (normalized to control) shown in the western blot analysis below.

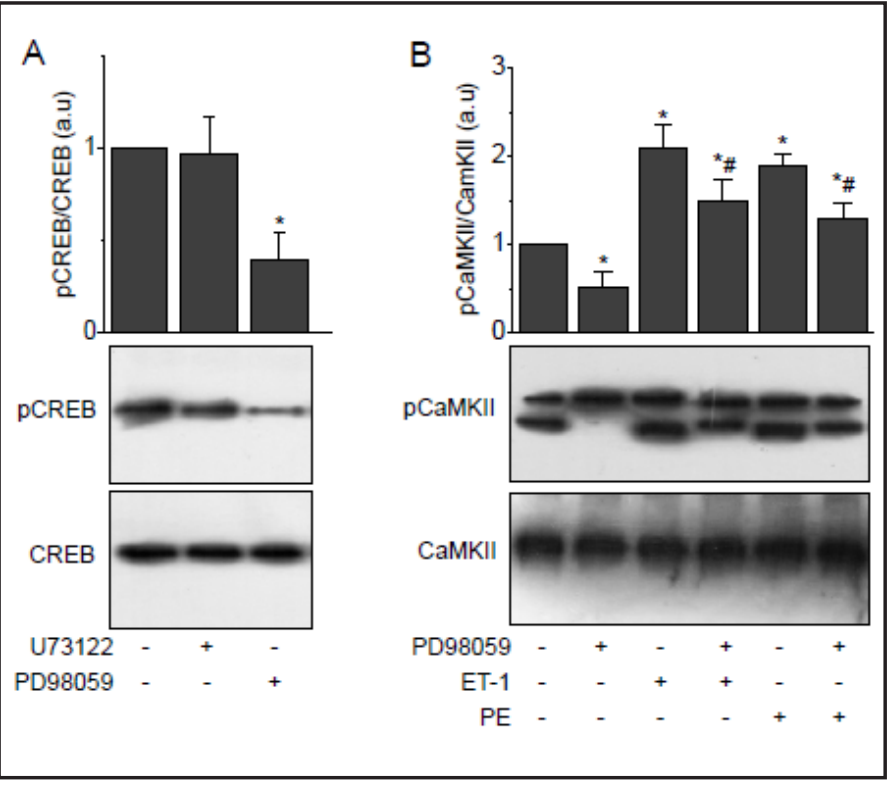

phosphorylation in the heart. It is assumed that $\mathrm{Ca}^{2+}$ release through the IP ${ }_{3} \mathrm{R} 2$ occurs around the nucleus, t-tubules and intercalated disks in ventricular myocytes, where IP ${ }_{3} \mathrm{R} 2$ molecules are localized $[4,6,7]$. Nuclear $\mathrm{Ca}^{2+}$, increased via $\mathrm{IP}_{3} \mathrm{R} 2$, is likely to directly regulate nearby CaMKII, known to co-localize with $\mathrm{IP}_{3} \mathrm{R} 2$ in the nuclear envelope in rat ventricular myocytes $[4,5]$. Pre-dominant peri-nuclear $\mathrm{Ca}^{2+}$ signal or loss of inner-nuclear envelope $\mathrm{Ca}^{2+}$ during the activation of $\mathrm{IP}_{3} \mathrm{Rs}$ using the direct $\mathrm{IP}_{3} \mathrm{R}$ activator, $\mathrm{IP}_{3} \mathrm{BM}$ or adenophostin, has been shown in ventricular myocytes [5, 39, 40]. Thus, it may be assumed that PE and ET-1 increase $\mathrm{Ca}^{2+}$ in the perinucleus more significantly than in other regions in rat ventricular myocytes. In addition, $\mathrm{IP}_{3} \mathrm{R}$-mediated $\mathrm{Ca}^{2+}$ releases can also facilitate $\mathrm{Ca}^{2+}$ spark occurrence via $\mathrm{Ca}^{2+}$ induced $\mathrm{Ca}^{2+}$ release $[29,41]$, and via other downstream signaling molecules such as CaMKII $[4,42]$. Such cytosolic $\mathrm{Ca}^{2+}$ increases are supposed to be more sensitive to BAPTA than nuclear $\mathrm{Ca}^{2+}$ changes and, thus, may be pertinent to the $\mathrm{Ca}^{2+}$-dependent (: BAPTA-sensitive) PKC/PKD-CaMKII-CREB signaling axis. Activation of CaMKII can phosphorylate the IP $_{3}$ R2 and decrease its open probability, which may feed back to shut off further $\mathrm{Ca}^{2+}$ release ([4]; Fig. 8). ERK1/2 phosphorylation was resistant to BAPTA, suggesting that ERK1/2 and IP ${ }_{3}$ 2 may interact directly or communicate in a restricted microdomain via local $\mathrm{Ca}^{2+}$. In the mouse cerebellum, type $1 \mathrm{IP}_{3} \mathrm{Rs}$ directly interact with ERK1/2 and ERK1/2 reduces IP ${ }_{3} \mathrm{R} 1$ activity by phosphorylation [43]. However, how ERK1/2 interacts with $\mathrm{IP}_{3} \mathrm{R} 2$ in cardiac myocytes requires further investigation.

In the present study, we demonstrated, for the first time, that CaMKII is critical for CREB activation under stimulation of $\alpha_{1}$-adrenoceptors or $\mathrm{ET}_{\mathrm{A}}$ receptors in cardiac myocytes. Because CREB activation is implicated in expression of hypertrophic marker genes [5, 35], our data provide a possible mechanism for CaMKII-mediated cardiac hypertrophy. It was previously reported that CaMKII is activated by both ET-1 [5] and PE [34]. It should be noted, however, that there is some controversy in the activation mechanisms for CaMKII in the presence of ET-1 and PE. ET-1-induced CaMKII activation was removed by $\mathrm{IP}_{3} \mathrm{R}$ blockade [5], whereas that by PE was suppressed by PKC inhibition [34]. We found that activation of CaMKII by both agonists was suppressed by inhibition of either PKC or IP ${ }_{3}$ Rs (Fig. 5A and C). Because treatment with either $\mathrm{Ca}^{2+}$ buffers or an inhibitor of $\mathrm{Ca}^{2+}$-dependent PKC/PKD eliminated both ET-1- and PE-induced CaMKII phosphorylation (Fig. 5B and C), it is plausible to think that $\mathrm{Ca}^{2+}$ increase due to the $\mathrm{IP}_{3} \mathrm{R}$-triggered $\mathrm{Ca}^{2+}$ releases may facilitate the activity of PKC/PKD, thereby stimulating CaMKII activation in the presence of ET-1 or PE. Recent evidence suggests activation of PKD by ET- 1 and PE and role of PKC-PKD signaling in cardiac hypertrophy [44, 45]. Possible role of PKD and/or PKC isozyme(s) in the signaling pathway 


\section{Cellular Physiology Cell Physiol Biochem 2017;41:399-412

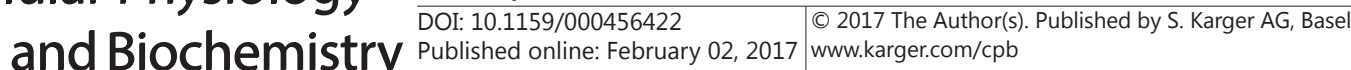 \\ Subedi et al.: Mechanisms for ET-1/PE-Mediated CREB Activation in Ventricle}

involving CaMKII-CREB under stimulation of $\alpha_{1}$-adrenoceptors and $\mathrm{ET}_{\mathrm{A}}$ receptors needs to be investigated.

We found a complete blockade of ET-1- or PE-induced CREB phosphorylation by PD98059, the ERK1/2 pathway inhibitor (Fig. 1B and C), which appears to be consistent with the previous reports [21,22]. However, it should be noted that PD98059 itself reduced levels of the phosphorylated forms of both CREB and CaMKII (Fig. 9). Blockade of CaMKII phosphorylation by PD98059 may suggest that the ERK1/2 pathway may be an upstream signaling for CaMKII activation. However, this is unlikely during stimulation of $\mathrm{ET}_{\mathrm{A}}$ receptors and $\alpha_{1}$-adrenoceptors, because ET-1- or PE-induced CaMKII phosphorylation, but not that of ERK1/2, was blocked by BAPTA or Gö6976 (Figs. 5-7). In addition, ET-1- or PEinduced CaMKII phosphorylation in the presence of PD98059 was still higher than CaMKII phosphorylation under PD98059 only (Fig. 9). Therefore, the pharmacological effects by PD98059 on ET-1- or PE-induced CREB phosphorylation may have been overestimated because of its nonspecific suppression of CaMKII that also mediates CREB phosphorylation. Important new finding in our study is that ERK1/2 activation under the stimulation of ET $_{A}$ receptors and $\alpha_{1}$-adrenoceptors is caused by the IP ${ }_{3} \mathrm{R} 2$ and $\mathrm{Ca}^{2+}$-independent PKC (Figs. $6 \mathrm{~B}$ and 7B). This ERK1/2 signaling upon activation of $\mathrm{ET}_{\mathrm{A}}$ receptors or $\alpha_{1}$-adrenoceptors appears to involve different upstream molecules than CaMKII signaling, such as $\mathrm{Ca}^{2+}$ and PKC isozymes. In addition, ERK1/2 appears to contribute significantly less than CaMKII to CREB activation under prolonged (15 $\mathrm{min})$ stimulation of these hormonal receptors. Considering the previous report showing that ET-1- or PE-induced ERK1/2 phosphorylation reaches a maximum at 1-2 min after application of these agonists, with a gradual decay after the maximum effects [24], the role of ERK1/2 may be more significant immediately after exposure to ET-1 or PE than it is later.

Although ET-1 and PE have been thought to induce ventricular hypertrophy [1, 5, 9-12, 46], signal transduction pathways for their activation of transcriptional regulators were poorly understood. Our study provide new evidence that the transcription factor CREB is activated mainly via $\mathrm{IP}_{3} \mathrm{R} 2$-mediated $\mathrm{Ca}^{2+}$ release and subsequent PKC/PKD-CaMKII signaling in ventricular myocytes (Fig. 8). In addition, our data suggest that activation of CREB by ET- 1 and PE is also partly regulated by $\mathrm{Ca}^{2+}$-independent PKC- and IP ${ }_{3} \mathrm{R} 2$-dependent ERK1/2 signaling in a separate compartment (Fig. 8). We propose that IP $\mathrm{P}_{3} \mathrm{Rs}$-PKC-CaMKIICREB signal transduction may be an important mechanism by which ET- 1 and $\alpha_{1}$-adrenergic agonist regulate gene expression of ventricular myocytes.

\section{Acknowledgements}

We thank Prof. Ju Chen at University of California, San Diego for $\mathrm{IP}_{3} \mathrm{R} 2 \mathrm{KO}$ mice. The work was supported by the National Research Foundation of Korea (NRF) grants funded by the Korea Government (MEST) (2015R1A2A2A01002625, 2009-0093815).

\section{Disclosure Statement}

The authors declare that there are no conflicts of interest.

\section{References}

1 Sugden P, Clerk A: Cellular mechanisms of cardiac hypertrophy. J Mol Med 1980;76:725-742.

2 Takanashi M, Endoh M: Concentration- and time-dependence of phosphoinositide hydrolysis induced by endothelin-1 in relation to the positive inotropic effect in the rabbit ventricular myocardium. J Pharmacol Exp Ther 1992;262:1189-1194.

-3 Terzic A, Pucéat M, Vassort G, Vogel SM: Cardiac alpha1-adrenoceptors: an overview. Pharmacol Rev 1993;45:147-175. 


\section{Cellular Physiology Cell Physiol Biochem 2017;41:399-412

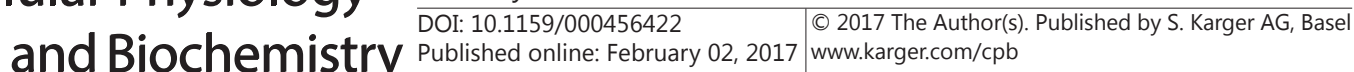

4 Bare DJ, Kettlun CS, Liang M, Bers DM, Mignery GA: Cardiac type 2 inositol 1,4,5-trisphosphate receptor: interaction and modulation by calcium/calmodulin-dependent protein kinase II. J Biol Chem 2005;280:15912-15920.

5 Wu X, Zhang T, Bossuyt J, Li X, McKinsey TA, Dedman JR, Olson EN, Chen J, Brown JH, Bers DM: Local InsP3dependent perinuclear $\mathrm{Ca}^{2+}$ signaling in cardiac myocyte excitation-transcription coupling. J Clin Invest 2006;116:675-682.

6 Kijima Y, Saito A, Jetton TL, Magnuson MA, Fleischer S: Different intracellular localization of inositol 1,4,5-trisphosphate and ryanodine receptors in cardiomyocytes. J Biol Chem 1993;268:3499-3506.

7 Mohler PJ, Davis JQ, Bennett V: Ankyrin-B coordinates the Na/K ATPase, Na/Ca exchanger, and Ins $\mathrm{P}_{3}$ receptor in a cardiac T-tubule/SR microdomain. PLoS Biol 2005;3:2158-2167.

-8 Rinne A, Blatter LA: Activation of NFATc1 is directly mediated by IP3 in adult cardiac myocytes. Am J Physiol Heart Circ Physiol 2010;299:H1701-H1707.

-9 Ramirez MT, Zhao XL, Schulman H, Brown JH: The nuclear deltaB isoform of $\mathrm{Ca}^{2+} /$ calmodulin-dependent protein kinase II regulates atrial natriuretic factor gene expression in ventricular myocytes. J Biol Chem 1997;272:31203-31208.

- 10 Zhu W, Zou Y, Shiojima I, Kudoh S, Aikawa R, Hayashi D, Mizukami M, Toko H, Shibasaki F, Yazaki Y, Nagai R, Komuro I: $\mathrm{Ca}^{2+} /$ calmodulin-dependent kinase II and calcineurin play critical roles in endothelin-1-induced cardiomyocyte hypertrophy. J Biol Chem 2000;275:15239-15245.

11 Colomer JM, Means AR: Chronic elevation of calmodulin in the ventricles of transgenic mice increases the autonomous activity of calmodulin-dependent protein kinase II, which regulates atrial natriuretic factor gene expression. Mol Endocrinol 2000;14:1125-1136.

12 Zhang T, Maier LS, Dalton ND, Miyamoto S, Ross J Jr, Bers DM, Brown JH: The $\delta_{\mathrm{C}}$ isoform of CaMKII is activated in cardiac hypertrophy and induces dilated cardiomyopathy and heart failure. Circ Res 2003;92:912-919.

13 Harzheim D, Movassagh M, Foo RS, Ritter O, Tashfeen A, Conway SJ, Bootman MD, Roderick HL: Increased Ins $\mathrm{P}_{3} \mathrm{Rs}$ in the junctional sarcoplasmic reticulum augment $\mathrm{Ca}^{2+}$ transients and arrhythmias associated with cardiac hypertrophy. Proc Natl Acad Sci USA 2009;106:11406-11411.

14 Sankar N, deTombe PP, Mignery GA: Calcineurin-NFATc regulates type 2 inositol 1,4,5-trisphosphate receptor (InsP ${ }_{3}$ R2) expression during cardiac remodeling. J Biol Chem 2014;289:6188-6198.

15 Gonzalez GA, Montminy MR: Cyclic AMP stimulates somatostatin gene transcription by phosphorylation of CREB at serine 133. Cell 1989;59:675-680.

16 Sheng M, Thompson MA, Greenberg ME: CREB: a Ca ${ }^{2+}$-regulated transcription factor phosphorylated by calmodulin-dependent kinases. Science 1991;252:1427-1430.

17 Tan Y, Rouse J, Zhang A, Cariati S, Cohen P, Comb MJ: FGF and stress regulate CREB and ATF-1 via a pathway involving p38 MAP kinase and MAPKAP kinase-2. EMBO J 1996;15:4629-4642.

18 Deak M, Clifton AD, Lucocq JM, Alessi DR: Mitogen- and stress-activated protein kinase-1 (MSK1) is directly activated by MAPK and SAPK2/p38, and may mediate activation of CREB. EMBO J 1998;17:4426-4441.

19 Wiggin GR, Soloaga A, Foster JM, Murray-Tait V, Cohen P, Arthur JS: MSK1 and MSK2 are required for the mitogen- and stress-induced phosphorylation of CREB and ATF-1 in fibroblasts. Mol Cell Biol 2002;22:2871-2881.

20 Kobrinsky E, Duong SQ, Sheydina A, Soldatov NM: Microdomain organization and frequency-dependence of CREB-dependent transcriptional signaling in heart cells. FASEB J 2011;25:1544-1555.

-21 Li B, Kaetzel MA, Dedman JR: Signaling pathways regulating murine cardiac CREB phosphorylation. Biochem Biophys Res Commun 2006;350:179-184.

-22 Harrison JG, Sugden PH, Clerk A: Endothelin-1 promotes phosphorylation of CREB transcription factor in primary cultures of neonatal cardiac myocytes: implications for the regulation of c-jun expression. Biochim Biophys Acta 2004;1644:17-25.

23 Markou T, Hadzopoulou-Cladaras M, Lazou A: Phenylephrine induces activation of CREB in adult rat cardiac myocytes through MSK1 and PKA signaling pathways. J Mol Cell Cardiol 2004;37:1001-1011.

-24 Markou T, Lazou A: Phosphorylation and activation of mitogen- and stress-activated protein kinase-1 in adult rat cardiac myocytes by G-protein-coupled receptor agonists requires both extracellular signalregulated kinase and p38 mitogen-activated protein kinase. Biochem J 2002;365:757-763.

25 Cárdenas C, Liberona JL, Molgó J, Colasante C, Mignery GA, Jaimovich E: Nuclear inositol 1,4,5-trisphosphate receptors regulate local $\mathrm{Ca}^{2+}$ transients and modulate cAMP response element binding 


\section{Cellular Physiology Cell Physiol Biochem 2017;41:399-412

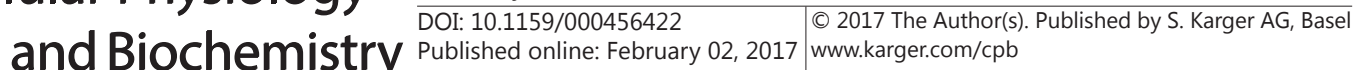

Subedi et al.: Mechanisms for ET-1/PE-Mediated CREB Activation in Ventricle

protein phosphorylation. J Cell Sci 2005;118:3131-3140.

-26 Müller M, Cárdenas C, Mei L, Cheung KH, Foskett JK: Constitutive cAMP response element binding protein (CREB) activation by Alzheimer's disease presenilin-driven inositol trisphosphate receptor (InsP3R) $\mathrm{Ca}^{2+}$ signaling. Proc Natl Acad Sci U S A 2011;108:13293-13298.

27 Francis H, Glaser S, DeMorrow S, Gaudio E, Ueno Y, Venter J, Dostal D, Onori P, Franchitto A, Marzioni M, Vaculin S, Vaculin B, Katki K, Stutes M, Savage J, Alpini G: Small mouse cholangiocytes proliferate in response to $\mathrm{H} 1$ histamine receptor stimulation by activation of the IP3/CaMK I/CREB pathway. Am J Physiol Cell Physiol 2008;295:C499-C513.

- 28 Kim JC, Woo SH: Shear stress induces a longitudinal $\mathrm{Ca}^{2+}$ wave via autocrine activation of $\mathrm{P}_{2} \mathrm{Y}_{1}$ purinergic signaling in rat atrial myocytes. J Physiol 2015;593.23:5091-5109.

29 Li X, Zima AV, Sheikh F, Blatter LA, Chen J: Endothelin-1-induced arrhythmogenic $\mathrm{Ca}^{2+}$ signaling is abolished in atrial myocytes of inositol-1,4,5-trisphosphate(IP3)-receptor type 2-deficient mice. Circ Res 2005;96:1274-1281.

- 30 Caivano M, Cohen P: Role of mitogen-activated protein kinase cascades in mediating lipopolysaccharidestimulated induction of cyclooxygenase- 2 and IL-1 $\beta$ in RAW264 macrophages. J Immunol 2000;164:30183025 .

31 Woo SH, Lee CO: Role of PKC in the effects of alpha1-adrenergic stimulation on $\mathrm{Ca}^{2+}$ transients, contraction, and L-type $\mathrm{Ca}^{2+}$ current in guinea-pig ventricular myocytes. Pflügers Arch 1999;437:335-344.

32 Woo SH, Lee CO: Effects of endothelin-1 on $\mathrm{Ca}^{2+}$ signaling in guinea-pig ventricular myocytes: role of protein kinase C. J Mol Cell Cardiol 1999;31:631-643.

- 33 Kockskämper J, Zima AV, Roderick HL, Pieske B, Blatter LA, Bootman MD: Emerging roles of inositol 1,4,5-trisphosphate signaling in cardiac myocytes. J Mol Cell Cardiol 2008;45:128-147.

- 34 O-Uchi J, Komukai K, Kusakari Y, Obata T, Hongo K, Sasaki H, Kurihara S: $\alpha 1$-adrenergic stimulation potentiates L-type current through $\mathrm{Ca}^{2+} /$ calmodulin-dependent PK II (CaMKII) activation in rat ventricular myocytes. Proc Natl Acad Sci U S A 2005;102:9400-9405.

- 35 Anderson ME, Brown JH, Bers DM: CaMKII in myocardial hypertrophy and heart failure. J Mol Cell Cardiol 2011;51:468-473.

-36 Bootman MD, Collins TJ, Mackenzie L, Roderick HL, Berridge MJ, Peppiatt CM: 2-Aminoethoxydiphenyl borate (2-APB) is a reliable blocker of store-operated $\mathrm{Ca}^{2+}$ entry but an inconsistent inhibitor of InsP $_{3}$ induced $\mathrm{Ca}^{2+}$ release. FASEB J 2002;16:1145-1150.

- 37 Hu HZ, Gu Q, Wang C, Colton CK, Tang J, Kinoshita-Kawada M, Lee LY, Wood JD, Zhu MX: 2-Aminoethoxydiphenyl borate is a common activator of TRPV1, TRPV2, and TRPV3. J Biol Chem 2004;34:35741-35748.

- 38 Zugaza JL, Sinnett-Smith J, Van Lint J, Rozengurt E: Protein kinase D (PKD) activation in intact cells through a protein kinase C-dependent signal transduction pathway. EMBO J 1996;15:6220-6230.

-39 Luo DL, Gao J, Lan XM, Wang G, Wei S, Xiao RP, Han QD: Role of inositol 1,4,5-trisphosphate receptors in $\alpha 1$ adrenergic receptor-induced cardiomyocyte hypertrophy. Acta Pharmacol Sin 2006;27:895-900.

40 Zima AV, Blatter LA: Inositol-1,4,5-trisphosphate-dependent $\mathrm{Ca}^{2+}$ signaling in cat atrial excitationcontraction coupling and arrhythmias. J Physiol 2004;555:607-615.

-41 Domeier TL, Zima AV, Maxwell JT, Huke S, Mignery GA, Blatter LA: IP ${ }_{3}$ receptor-dependent $\mathrm{Ca}^{2+}$ release modulates excitation-contraction coupling in rabbit ventricular myocytes. Am J Physiol Heart Circ Physiol 2008;294:H596-H604.

-42 Wehrens XH, Lehnart SE, Reiken SR, Marks AR: $\mathrm{Ca}^{2+} /$ calmodulin-dependent protein kinase II phosphorylation regulates the cardiac ryanodine receptor. Circ Res 2004;94:e61-e70.

43 Bai GR, Yang LH, Huang XY, Sun FZ: Inositol 1,4,5-trisphosphate receptor type 1 phosphorylation and regulation by extracellular signal-regulated kinase. Biochem Biophys Res Commun 2006;348:1319-1327.

-44 Haworth RS, Goss MW, Rozengurt E, Avkiran M: Expression and activity of protein kinase D/protein kinase $\mathrm{C} \mu$ in myocardium: evidence for $\alpha_{1}$-adrenergic receptor- and protein kinase C-mediated regulation. J Mol Cell Cardiol 2000;32:1013-1023.

-45 Bossuyt J, Chang CW, Helmstadter K, Kunkel MT, Newton AC, Campbell KS, Martin JL, Bossuyt S, Robia SL, Bers DM: Spatiotemporally distinct protein kinase D activation in adult cardiomyocytes in response to phenylephrine and endothelin. J Biol Chem 2011;286:33390-33400.

46 Wang YS, Zhou J, Hong K, Cheng XS, Li YG: MicroRNA-223 displays a protective role against cardiomyocyte hypertrophy by targeting cardiac troponin I-interacting kinase. Cell Physiol Biochem 2015;35:1546-1556. 